\title{
CARACTERÍSTICAS MICROBIOLÓGICAS DO SUCO DE LARANJA IN NATURA ${ }^{1}$
}

\author{
Juliana C. OLIVEIRA², Pedro SETTI-PERDIGÃO³, Karina A.G. SIQUEIRA², \\ Antônio C. SANTOS ${ }^{2}$, Marco A.L. MIGUEL ${ }^{2, *}$
}

\begin{abstract}
RESUMO
Sucos de laranja frescos são amplamente consumidos, devido ao seu sabor agradável e por representar uma importante fonte de vitamina C, minerais e carboidratos. Essas características tornam o suco um meio propício ao desenvolvimento de microrganismos, incluindo patógenos capazes de sobreviver em ambientes ácidos, como E. coli, Salmonella e Listeria monocytogenes. A qualidade microbiológica do suco de laranja pode ser avaliada pela contagem de bactérias mesófilas heterotróficas totais, bactérias ácidoláticas (BAL), bolores e leveduras, coliformes totais e fecais, além da detecção direta de patógenos. Neste trabalho foi realizado o acompanhamento dessas características para 50 amostras de suco fresco de marcas comercializadas no Rio de Janeiro. As amostras foram adquiridas e mantidas sob refrigeração a $4^{\circ} \mathrm{C}$, até o momento das análises. Além das contagens mencionadas, foi realizada a pesquisa de E. coli e Salmonella sp. As contagens de microorganismos mesófilos heterotróficos e BAL, para a maioria das amostras, mostraram-se em níveis elevados. O nível de coliformes fecais em $15 \%$ das amostras foi acima do permitido pela legislação. Os perfis de susceptibilidade a antimicrobianos de coliformes isolados estavam dentro do previsto para amostras ambientais ou fecais não submetidas a grande pressão seletiva.

Palavras-chave: suco de laranja, qualidade, coliformes, Salmonella sp.
\end{abstract}

\section{SUMMARY}

MICROBIOLOGICAL CHARACTERISTICS OF ORANGE JUICES. Fresh orange juices are very popular as a source of vitamin C, minerals and carbohydrates. However, for the same reasons, they are a suitable environment for the microorganism growth, including pathogens that are able to survive in such conditions, as E. coli, Salmonella and Listeria monocytogenes. To assure the quality of these products, microbiological safety monitoring is needed, through measuring lactic acid bacteria (LAB), moulds and yeasts, total and fecal coliforms and total plate counts. These parameters were monitored for 50 fresh juice samples commercialized in Rio de Janeiro, Brazil. The samples were acquired and maintained under refrigerated conditions. Tests were also made for the detection of $E$. coli and Salmonella sp. The LAB and total plate counts were, for the most of the samples, higher than the expected. The fecal coliforms levels of $15 \%$ of the samples were above those permitted by law. The susceptibility patterns for fecal coliforms isolates were as the expected to environmental or fecal samples that were not under selective pressure.

Keywords: orange juice, quality, coliforms, Salmonella sp.

\section{1 - INTRODUÇÃO}

O mercado mundial de laranja possui duas regiões produtivas altamente significativas: Flórida (EUA) e São Paulo (Brasil). Juntas, essas regiões respondem por $40 \%$ da produção mundial da fruta e seus derivados. O Brasil, maior produtor e exportador de suco de laranja, detém $50 \%$ da produção mundial, sendo que apenas $3 \%$ ficam no mercado interno. O amplo consumo do suco de laranja deve-se ao sabor agradável conjugado às suas características nutricionais: é fonte de vitamina $\mathrm{C}$, minerais $\mathrm{e}$ carboidratos, sendo, portanto, indicado para convalescentes, idosos e considerado importante complemento alimentar em dietas infantis. Estudos in vitro e in vivo evidenciaram o efeito protetor do suco de laranja contra desordens alérgicas e inflamatórias, doenças cardiovasculares e câncer. Estes efeitos têm sido associados a elevadas concentrações de

\footnotetext{
$\overline{{ }^{1} \text { Recebido para publicação em 21/01/2004. Aceito para publicação em }}$ 28/04/2006 (001276)

${ }^{2}$ Instituto de Microbiologia Professor Paulo de Góes, Departamento de Microbiologia Médica

${ }^{3}$ Instituto de Ciências Biomédicas, Departamento de Farmacologia Básica e Clínica da Universidade Federal do Rio de Janeiro (RJ)

CEP 21941-590

E-mail:marco.miguel@micro.ufrj.br

*A quem a correspondência deve ser enviada
}

flavanonas, compostos raramente encontrados em outras frutas e vegetais [10].

A população microbiana do suco de laranja é derivada de fatores que vão desde as etapas de produção primária da fruta até o preparo de seu suco para o consumo final [3, 19]. Bactérias ácido-láticas (BAL) e leveduras são os microorganismos que melhor se adaptam ao ambiente de baixo $\mathrm{pH}$ e altas concentrações de açúcares, ambiente característico do suco de laranja, com pH baixo, são os principais responsáveis pela deterioração do produto. Os gêneros Lactobacillus e Leuconostoc são os representantes mais comuns dentro do grupo das BAL [16]; os gêneros mais representativos de leveduras são Saccharomyces e Candida [8, 14].

As condições higiênicas, associadas à estocagem das laranjas e à etapa de extração, comprometem a segurança microbiológica do suco. A elevada acidez do suco de laranja oferece um ambiente inóspito e seletivo para um grande número de patógenos, mas seu consumo tem sido associado a casos de doenças de origem alimentar. Na Flórida (EUA), um surto causado por Salmonella sorotipo Anatum foi associado ao consumo de suco de laranja não pasteurizado [11]. Outros dois casos, também na Flórida, tiveram como agente etiológico Salmonella sp., e os resultados indicaram más condições sanitárias da indústria local de processa- 
mento de cítricos como a principal causa [15]. Em 1998, um surto causado por Shigella flexneri foi atribuído ao consumo de suco de laranja fresco, entre visitantes de um parque na África do Sul [21]. No ano seguinte, 15 estados norte-americanos e duas províncias canadenses reportaram surto de salmonelose, também associado ao consumo de suco não pasteurizado, em que 207 casos foram confirmados para Salmonella sorotipo Muenchen [5].

Embora já tenha sido demonstrada a presença de coliformes fecais em sucos de laranja comercializados [1, 17], não há estudos epidemiológicos que associem o consumo de laranja a doenças de origem alimentar no Brasil.

Alguns autores associam o consumo de alimentos vegetais como fontes de bactérias resistentes a antimicrobianos, principalmente da família Enterobacteriaceae, encontradas em amostras fecais de humanos saudáveis, mesmo na ausência de seleção por uso de terapia antimicrobiana [7, 12].

O presente trabalho tem como objetivo avaliar as características microbiológicas de sucos de laranja in natura comercializados na cidade do Rio de Janeiro. Este tipo de suco não sofre processamento posterior ao seu preparo; a extração do suco ocorre com a introdução da fruta íntegra em máquinas extratoras, no local de comercialização. Os parâmetros analisados foram: contagem de microorganismos aeróbios mesófilos, estritos e facultativos viáveis; bolores e leveduras; BAL e coliformes totais e termotolerantes; análise da presença de E. coli e Salmonella sp. Em adição, foram realizadas a identificação dos coliformes termotolerantes isolados e caracterização de seu perfil de susceptibilidade a antimicrobianos.

\section{2 - MATERIAL E MÉTODOS}

\section{1 - Amostragem}

Cinqüenta amostras de suco de laranja foram obtidas em 10 estabelecimentos comerciais situados na cidade do Rio de Janeiro.

\section{2 - Amostras padrão}

No controle dos experimentos e na validação dos meios de cultivo, foram utilizados os seguintes microorganismos: Escherichia coli American Type Culture Collection (ATCC) 25922 e Salmonella ATCC 10749, mantidas em ágar nutriente inclinado; Enterococcus faecalis ATCC 6569, mantido em ágar BHI inclinado; Lactobacillus casei ATCC 393, mantido em ágar MRS inclinado; e Listeria innocua, amostras LI-01 e 02, pertencentes à coleção de nosso laboratório, mantidas em BHI inclinado.

\section{3 - Análises realizadas}

As análises foram baseadas em metodologia descrita no Compendium of methods for the microbiological examination of foods [22].

\subsection{1 - Determinação do $\mathbf{p H}$ dos sucos}

$\mathrm{O}$ pH foi determinado diretamente com pHmetro Quimis modelo 0.400.A.

\subsection{2 - Contagem de microorganismos}

Foram utilizados os meios de cultura Ágar Padrão para Contagem (APC), Ágar Batata Dextrosado (ABD), Ágar MRS, Caldo Lactose Bile Verde Brilhante $2 \%$ para realizar as contagens de microorganismos aeróbios mesófilos estritos e facultativos viáveis totais, bolores e leveduras, BAL e coliformes totais, respectivamente.

\subsection{3 - Análises de coliformes fecais}

\subsubsection{1 - Isolamento e identificação de coliformes fecais}

Foi realizada a semeadura por esgotamento de um inóculo obtido a partir do crescimento em cada tubo contendo caldo EC positivo para placas contendo ágar eosina azul de metileno (EMB). Após incubação a $37^{\circ} \mathrm{C}$ por $24 \mathrm{~h}$, colônias características de coliformes fecais foram transferidas para ágar nutriente para posterior caracterização bioquímica. Os seguintes parâmetros foram utilizados para diferenciação: produção de ácidos ou acetoína, a partir da fermentação da glicose; produção de indol, mobilidade a $37^{\circ} \mathrm{C}$ e descarboxilação da lisina; utilização do citrato como única fonte de carbono; fermentação de lactose, sacarose, produção de $\mathrm{H}_{2} \mathrm{~S}$ e fermentação da glicose, acompanhada de produção de $\mathrm{CO}_{2}$; e presença das enzimas urease e triptofanase.

Os perfis das amostras nos diferentes meios foram utilizados para definir sua classificação taxonômica, segundo descrito em Manual of Clinical Microbiology [2].

As estirpes também foram identificadas bioquimicamente com as galerias de identificação API $20 \mathrm{E}$ (bioLab Mérieux).

\subsubsection{2 - Pesquisa de cepas de E. coli diarreiogênicas}

Amostras isoladas como coliformes termotolerantes e que apresentassem perfil bioquímico característico de E. coli foram testadas por aglutinação contra os seguintes anti-soros: polivalentes clássica A, clássica B, clássica C, invasora A, invasora B e monovalentes O124 e O157.

\subsection{4 - Determinação do perfil de susceptibilidade aos antimicrobianos das amostras isoladas}

O teste de difusão em disco foi utilizado como ensaio de susceptibilidade, segundo metodologia descrita pelo National Comittee for Clinical Laboratory Standards [13]. As amostras foram testadas contra os seguintes antimicrobianos: amicacina (30 $\mu \mathrm{g})$, amoxicilina+ácido clavulânico (30 $\mu \mathrm{g}$ ), ampicilina (10 $\mathrm{g}$ ), aztreonama (30 $\mu \mathrm{g})$, carbenicilina (100 $\mu \mathrm{g})$, cefalotina (30 $\mu \mathrm{g})$, cefepime (30 $\mu \mathrm{g})$, cefoperazona (75 $\mathrm{g}$ ), cefotaxima (30 $\mu \mathrm{g}$ ), cefotriaxona (30 $\mu \mathrm{g}$ ), ciproflo- 
xacina (5 $\mu \mathrm{g})$, cotrimoxazol (25 $\mu \mathrm{g})$, gentamicina (10 $\mu \mathrm{g})$, imipenem ( $10 \mu \mathrm{g})$, norfloxacina (10 $\mu \mathrm{g})$, ofloxacina (5 $\mu \mathrm{g})$.

\section{3 - RESULTADOS E DISCUSSÃO}

Apesar do baixo pH (valor médio de 3,5), surtos de doenças de origem alimentar têm sido relacionados ao consumo de suco de laranja não pasteurizado $[5,6,11,15$, 21]. Os resultados obtidos neste estudo evidenciaram altas contagens de mesófilos, variando entre $10^{5}$ e $10^{6} \mathrm{UFC} / \mathrm{mL}$, em $74 \%$ das amostras analisadas (Figura 1). As altas contagens obtidas podem indicar falhas nos processos de sanitização dos analisados, uma vez que a mesma análise, realizada em sucos de laranja frescos e processados, preparados a partir de frutas sanitizadas, evidenciou valores entre $10^{4}$ e $10^{5} \mathrm{UFC} / \mathrm{mL}$ [18]. Resultados semelhantes foram observados para as contagens de bolores e leveduras e BAL. O percentual de amostras entre $10^{4}$ e $10^{5} \mathrm{UFC} / \mathrm{mL}$ foi de 41,7 e 52,1\%, respectivamente (Figuras 2 e 3). Análises realizadas em suco de laranja comercializado em lanchonetes e restaurantes de São Paulo (Brasil) apresentaram contagens variando entre $10^{5}$ e $10^{6} \mathrm{UFC} / \mathrm{mL}$ em $45 \%$ das amostras [9].

Alguns locais de comercialização não apresentavam, visivelmente, as máquinas extratoras em condições higiênicas adequadas. Em sete estabelecimentos (B, C, F, G, H, I e J), o suco era engarrafado no momento da comercialização. Nos estabelecimentos A, D e E, os sucos eram comercializados previamente embalados. As garrafas vazias utilizadas no envase do suco para comercialização encontravam-se estocadas abertas, ao ar livre. Em alguns estabelecimentos, tanto os recipientes quanto as tampas eram manipulados sem luvas. Os sucos dos estabelecimentos B e I apresentaram baixas contagens de mesófilos, BAL e bolores e leveduras. Os sucos dos estabelecimentos C, H e G apresentaram, para a maioria das amostras, contagens acima de $10^{5}$, algumas vezes atingindo valores da ordem de $10^{6}$. Adotando estratégias de sanitização e melhorando as condições de estocagem de frutas e materiais, tanto a microbiota normal quanto possíveis patógenos poderiam ser reduzidos.

Os valores de $\mathrm{pH}$ encontrados para as diferentes amostras situaram-se na faixa entre 3,11 e 4,04. Apenas duas amostras (pH 3,11 e 3,45) apresentavam baixas contagens de mesófilos aeróbios totais, mas estes dados não foram suficientes para que o $\mathrm{pH}$ do suco pudesse ser considerado fator significativo para a inibição da presença de microorganismos, uma vez que outras amostras, com valores de pH menores que 3,45 apresentaram altas contagens de mesófilos totais.

Entre as amostras analisadas, 37 (74\%) apresentaram número detectável de coliformes totais, tendo sido encontradas contagens superiores a $10^{3} \mathrm{NMP} / \mathrm{mL}$ em 19 amostras (38\%). Quanto à análise de coliformes termotolerantes, 30\% apresentaram concentrações variando entre 36 e 1,1x10 $\mathrm{NMP} / \mathrm{mL}$; destas, $57 \%$ apresentaram contagens superiores a $10^{2} \mathrm{NMP} / \mathrm{mL}$, estando em desacordo com a legislação vigente [4]. Os valores encontrados para coliformes totais e termotolerantes estão representados nas Figuras 4 e 5.

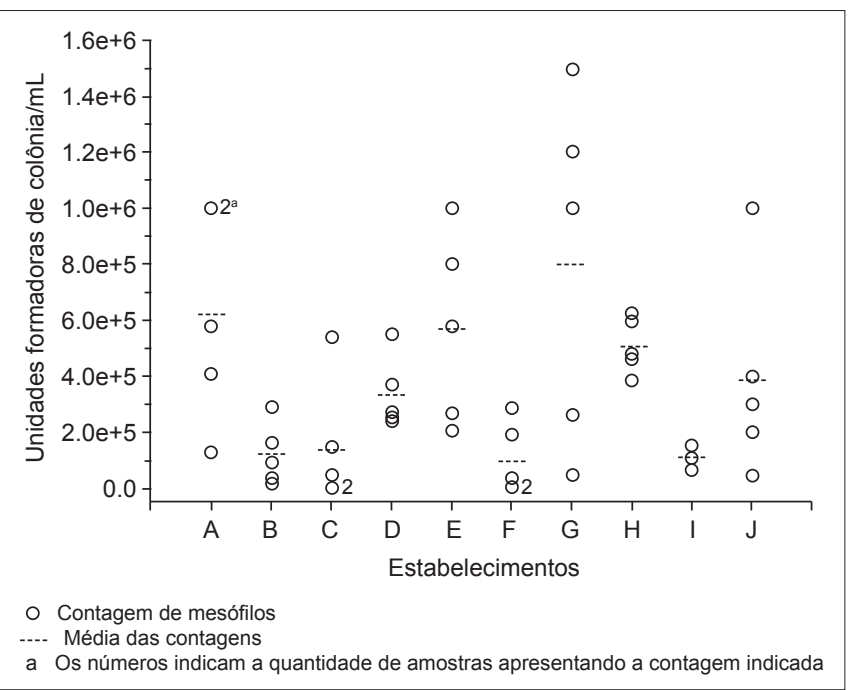

FIGURA 1 - Contagem de mesófilos em amostras de suco de laranja in natura comercializado no Rio de Janeiro

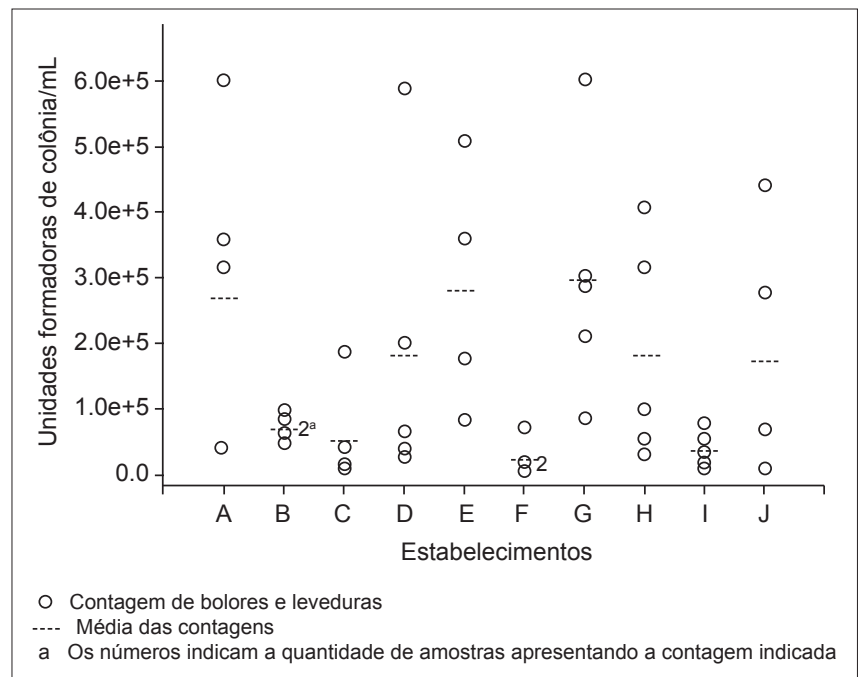

FIGURA 2 - Contagem de bolores e leveduras em amostras de suco de laranja in natura comercializado no Rio de Janeiro

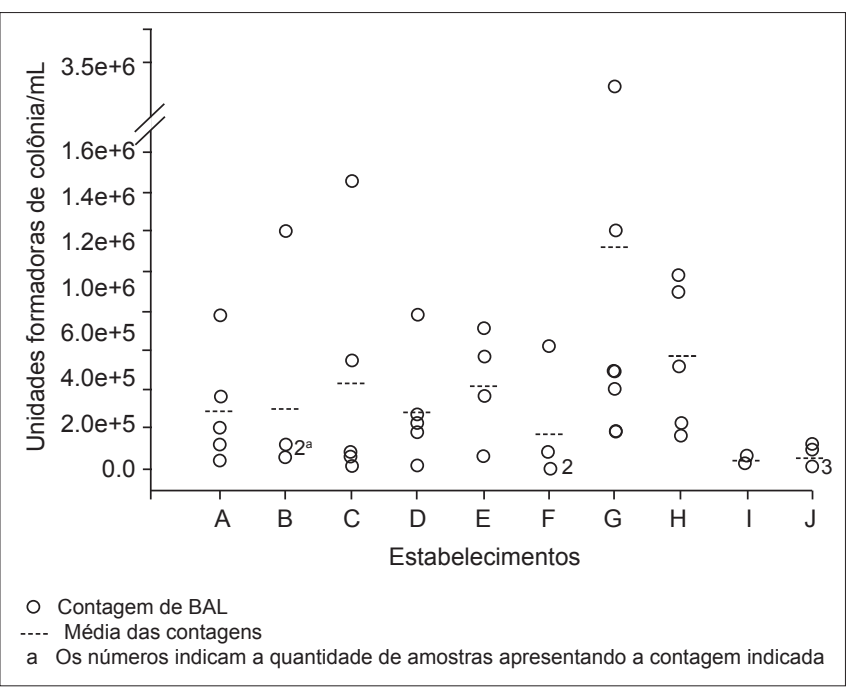

FIGURA 3 - Contagem de BAL em amostras de suco de laranja in natura comercializado no Rio de Janeiro 


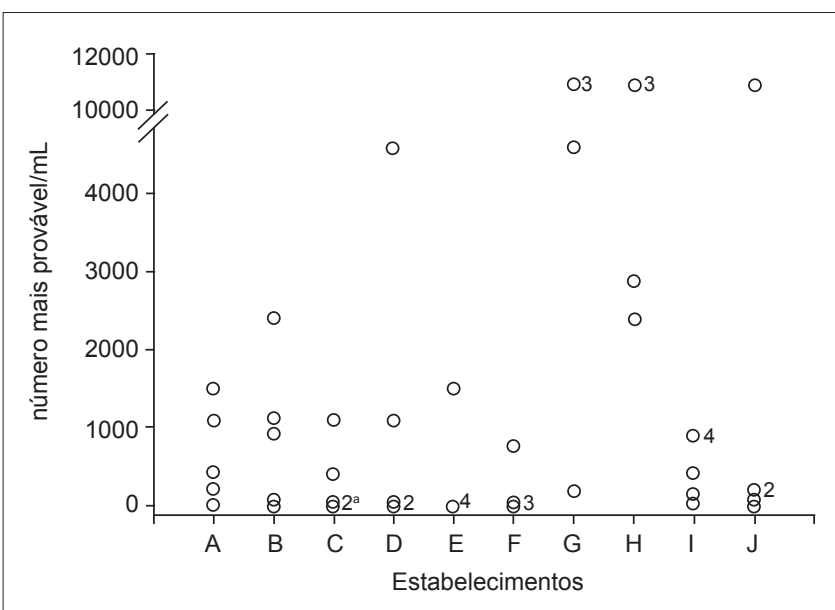

- Contagem de coliformes totais

a Os números indicam a quantidade de amostras apresentando a contagem indicada

FIGURA 4 - Contagem de coliformes totais em amostras de suco de laranja in natura comercializado no Rio de Janeiro

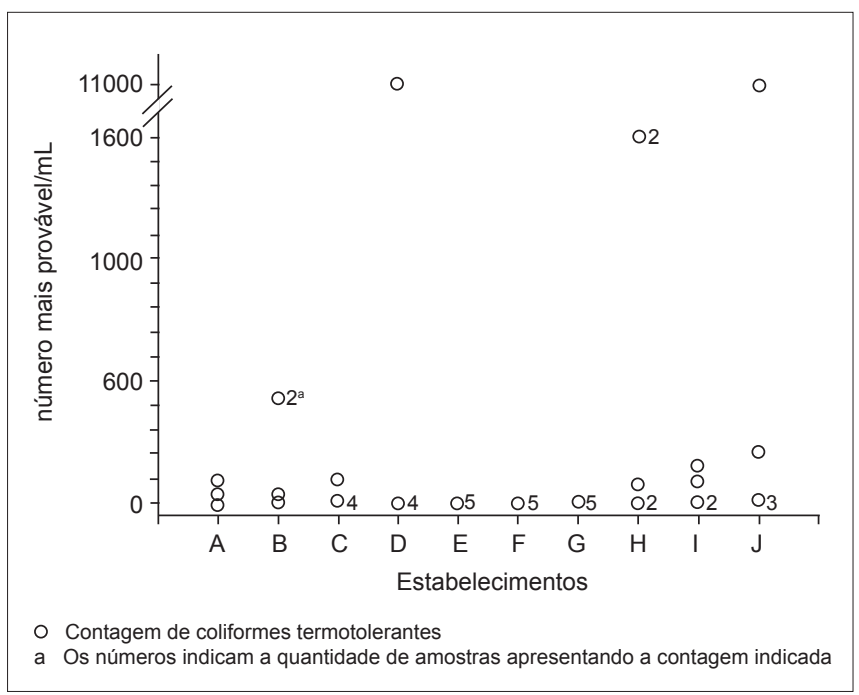

FIGURA 5 - Contagem de coliformes termotolerantes em amostras de suco de laranja in natura comercializado no Rio de Janeiro

Foram isoladas 55 cepas de coliformes termotolerantes a partir das 14 amostras de suco que apresentaram

contagem, sendo uma identificada como Escherichia coli e 54 como Klebsiella pneumoniae. Apesar de sua capacidade de aglutinar o soro contra o sorotipo O157, a cepa de E. coli isolada, quando estudada e comparada com as características do fenótipo O157:H7, não foi identificada como tal, uma vez que o isolado apresentou-se capaz de fermentar o sorbitol e produzir a enzima ß-glucoronidase.

As contagens obtidas para coliformes termotolerantes sustentam a afirmação de que os sucos foram submetidos a condições inadequadas de manipulação e/ou estocagem. A presença destes últimos indica o contato do alimento com material fecal, direta ou indiretamente, sugerindo a possível presença de outros enteropatógenos, incluindo bactérias e vírus enteropatogênicos. Não foi detectada a presença de Salmonella spp. em nenhuma das amostras.

Em nosso estudo, as estirpes de Klebsiella e E. coli mostraram um perfil de susceptibilidade aos antimicrobianos sem marcadores importantes de resistência. O perfil de sensibilidade à maioria dos antimicrobianos e a resistência à ampicilina e carbenicilina apresentada por 64,6 e 93,7\% das amostras, respectivamente, estão de acordo com o esperado para amostras ambientais de Klebsiella [20]. Foram encontrados seis diferentes perfis de multirresistência, todos apresentando resistência à ampicilina e carbenicilina, além de: Amoxicilina + ácido clavulânico (5,45\%); Cotrimoxazol (3,64\%); Amoxicilina + ácido clavulânico e cefalotina (1,82\%); Amoxicilina + ácido clavulânico e cotrimoxazol (3,64\%); cefalotina e cotrimoxazol (1,82\%); Amoxicilina + ácido clavulânico, cefalotina e cotrimoxazol (1,82\%). O gênero Klebsiella apresenta resistência cromossômica a antimicrobianos da classe dos beta-lactâmicos, o que explica sua alta resistência a ampicilina e carbenicilina [2]. Os perfis encontrados condizem com aqueles de cepas de Klebsiella isoladas de amostras humanas, em casos de baixa pressão seletiva pelo uso intenso de terapia antimicrobiana [20].

\section{4 - CONCLUSÕES}

- Algumas amostras apresentaram altas contagens de microorganismos, indicativas de condições inadequadas de manipulação e estocagem do produto, levando a um risco associado à possível existência de patógenos capazes de sobreviver em ambiente ácido;

- algumas amostras foram consideradas impróprias para consumo, devido à concentração de coliformes fecais serem superiores àquelas permitidas pela legislação vigente;

- $\quad$ cepas de coliformes fecais isoladas apresentaram perfil de susceptibilidade a antimicrobianos sem importantes marcadores de resistência;

- $\quad$ é necessário um controle maior relativo ao processo produtivo, objetivando melhorar a qualidade do suco de laranja comercializado, evitando conseqüências danosas tanto à saúde do consumidor quanto à durabilidade do produto. Entre as medidas que poderiam ser aplicadas como controle estão a sanitização de equipamentos, frutas e superfícies de contato e boas práticas de produção, além de treinamento dos funcionários e fiscalização dos estabelecimentos.

\section{5 - REFERÊNCIAS BIBLIOGRÁFICAS}

[1] ALMEIDA, R.B.; GUIMARÃES, R.P.; CASTRO, R.E.S.; BERNARDI, M.R.V.; SOARES, M.; ARAÚJO, K.G.L. Estudo da qualidade microbiológica, físico-química e sensorial de suco de laranja fresco envasado em garrafas plásticas. Revista Higiene Alimentar, v. 17, p. 68-72, 2003. 
[2] BALOWS, A.; HAUSLER Jr., W.J.; HERRMAN, K.L.; ISENBERG, H.D. \& SHADOMY, H.J. Manual of Clinical Microbiology, $5^{\text {a }}$ ed. Washington: American Society for Microbiology, 1995.

[3] BRACKETT, R.E. Shelf stability and safety of fresh produce as influenced by sanitation and disinfection. J. Food Prot., v. 55, p. 808-814, 1992.

[4] BRASIL. Agência Nacional de Vigilância Sanitária. www.anvisa.gov.br/legis/resol/12_01rdc.htm. 2001.

[5] CENTERS FOR DISEASE CONTROL. Outbreak of Salmonella serotype Muenchen infections associated with unpasteurized orange juice - United States and Canada, June 1999. JAMA., v. 282, p. 726-8. 1999.

[6] COOK, K.A.; DOBBS, T.E.; HLADY, G.; WELLS, J.G.; BARRET, T.J.; PUHR, N.D.; LANCETTE, G.A.; BODAGER, D.W.; TOTH, B.L.; GENESE, C.A.; HIGHSMITH, A.K.; PILOT, K.E.; FINELLI, L. \& SWERDLOW, D.L. Outbreak of Salmonella serotype Harford infections associated with unpasteurized orange juice. J. Am. Med. Assoc., v. 280, p. 1.504-1.509, 1998.

[7] CORPET, D.E. Antibiotic resistance from food. N. Engl. J. Med., v. 318, p. 1.206-1.207. 1988.

[8] FAVILLE, L.W. Survival of microorganisms in concentrated orange juice. Food Technol., v. 5, p. 3-36, 1951.

[9] FURLANETTO, S.; PAULA, C.R.; GAMBALE, W.; NASCIMENTO, D. Ocorrências de bolores e leveduras em sucos de laranja ao natural. Rev. Bras. Microbiol., v. 13, p. 31-34, 1982.

[10] GIL-IZQUIERDO, A.; GIL, M.I. \& FERRERES, F. Effect of processing techniques at industrial scale on orange juice antioxidant and beneficial health compounds. J. Agric. Food. Chem., v. 50, p. 5.107$5.114,2002$.

[11] KRAUSE, G.; TERZAGIAN, R. \& HAMMOND, R. Outbreak of Salmonella serotype Anatum infection associated with unpasteurized orange juice. South Med. J. Dec., v. 94, p. 1.168-1.172, 2001.

[12] LEVY, S.B.; MARSHALL, B.; SCHLUDERBERG, S.; ROWSE, D. \& DAVIS, J. High frequency of antimicrobial resistance in human fecal flora. Antimicrob. Agents Chemother., v. 32, p. 1.801-1.806, 1988.
[13] NATIONAL COMMITTEE FOR CLINICAL LABORATORY STANDARDS (NCCLS). Performance standards of antimicrobial susceptibility tests. Approved Standards, Villanova, USA. 2002.

[14] PARISH, M.E. Microbiological concerns in citrus juice processing. Food Technol., v. 45, p. 128-132, 1991.

[15] PARISH, M.E. Coliforms, Escherichia coli and Salmonella serovars associated with a citrus-processing facility implicated in a salmonellosis outbreak. J. Food. Prot., v. 61, p. 280-284, 1998.

[16] PARISH, M.E. \& HIGGINS, D. Isolation and identification of lactic acid bacteria from samples of citrus molasses and unpasteurized orange juice. J. Food Sci., v. 53, p. 645-646, 1988.

[17] RUSCHEL, C.K., CARVALHO, H.H., SOUZA, R.B. \& TONDO, E.C. Qualidade microbiológica e físico-química de sucos de laranja comercializados nas vias públicas de Porto Alegre (RS). Revista Ciência e Tecnologia, v. 21, p. 3, 2001.

[18] SADLER,G.D.; PARISH, M.E. \& WICKLER, L. Microbial, enzymatic and chemical changes during storage of fresh and processed orange juice. J. Food Sci., v. 57, p. 1.187-91, 1992.

[19] SANTOS, A.C.; AlMEIDA, A.S.; PEREIRA, C.Q.; LOPES, M.L.M.; MESQUITA, V.L.V. \& MIGUEL, M.A.L. Estabilidade microbiológica do suco de laranja: efeito de diferentes tratamentos de sanitização das laranjas e viabilidade dos patógenos. Apresentado em Simpósio Internacional de Segurança Microbiológica dos Alimentos, 2002.

[20] STOCK, I. \& WIEDEMANN, B. Natural susceptibility of Klebsiella pneumoniae, K. oxytoca, K. planticola, $K$. ornithinolytica and $K$. terrigena strains. J. Med. Microbiol., v. 50, p. 396-406, 2001.

[21] THURSTON, H., STUART, J., MCDONNELL, B.; NICHOLAS, S. \& CHEASTY, T. Fresh orange juice implicated in an outbreak of Shigella flexneri among visitors to a South African game reserve. J. Infect., v. 36, p. 350, 1998.

[22] VANDERZANT, C. \& SPLiTTSTOESSER, D.F. Compendium of methods for the microbiological examination of foods. Washington D.C.: American Public Health Association, 1992. 